\title{
Protective effects of caffeic acid phenethyl ester on the heart in experimental periodontitis against oxidative stress in rats
}

\author{
Umut Yiğitt ${ }^{1, A-F}$, Fatma Yeşim Kırzıoğlu ${ }^{2, A-F}$, Özlem Özmen ${ }^{3, B, C, F}$, Abdülhadi Cihangir Uğuz, ${ }^{4, B, C, F}$ \\ ${ }^{1}$ Department of Periodontology, School of Dentistry, Uşak University, Turkey \\ 2 Department of Periodontology, School of Dentistry, Süleyman Demirel University, Isparta, Turkey \\ ${ }^{3}$ Department of Pathology, School of Veterinary Medicine, Mehmet Âkif Ersoy University, Burdur, Turkey \\ ${ }^{4}$ Department of Biophysics, School of Medicine, Yozgat Bozok University, Yozgat, Turkey \\ A - research concept and design; $\mathrm{B}$ - collection and/or assembly of data; $\mathrm{C}$ - data analysis and interpretation; \\ $D$ - writing the article; $E$ - critical revision of the article; $F$ - final approval of the article
}

Address for correspondence

Umut Yiğit

E-mail: umut.yigit@usak.edu.tr

Funding sources

This study was supported by the Scientific Projects Research Unit of Süleyman Demirel University, Isparta, Turkey (grant No. 3243-D1-12).

Conflict of interest

None declared

Received on September 25, 2020

Reviewed on December 18, 2020

Accepted on January 13, 2021

Published online on September 30, 2021

Cite as

Yiğit U, Kırzıoğlu FY, Özmen 0̈, Uğuz AC. Protective effects of caffeic acid phenethyl ester on the heart in experimental periodontitis against oxidative stress in rats. Dent Med Probl. 2021;58(3):335-341. doi:10.17219/dmp/132388

DOI

$10.17219 / \mathrm{dmp} / 132388$

Copyright

○) 2021 by Wroclaw Medical University

This is an article distributed under the terms of the

Creative Commons Attribution 3.0 Unported License (CC BY 3.0)

(https://creativecommons.org/licenses/by/3.0/).

\begin{abstract}
Background. Caffeic acid phenethyl ester (CAPE) may be considered as alternative treatment for periodontitis and benefit the heart by way of its ameliorative effects.

Objectives. The aim of the study was to evaluate the effects of CAPE on cytokine levels and the oxidative status in the serum and heart tissue in a rat model of periodontitis.

Material and methods. Experimental animals were randomly assigned to 3 groups: control group $(C ; n=8) ;$ periodontitis group $(P ; n=10)$; and periodontitis + CAPE group (PC; $n=10)$. Caffeic acid phenethyl ester, at a dose of $10 \mu \mathrm{mol} / \mathrm{kg} / \mathrm{day}$, was administered by intraperitoneal injection over a 14-day period. Interleukin (IL)-1B, LL-10 and tumor necrosis factor-alpha (TNF-a) were assessed in the serum. Glutathione (GSH), glutathione peroxidase (GSH-Px) and malondialdehyde (MDA) were assessed in both the serum and the heart tissue homogenate.
\end{abstract}

Results. Increased IL-1 1 , IL-10 and TNF-a serum levels were observed in the $P$ group $(p<0.05)$. Caffeic acid phenethyl ester significantly decreased alveolar bone loss (ABL) and cytokine levels in the PC group $(p<0.05)$. Malondialdehyde, one of the strongest oxidants, was significantly decreased in the PC group as compared to the $P$ group $(p<0.05)$. In both the serum and the heart tissue homogenate there were no differences in MDA levels between the $P C$ and $C$ groups. Furthermore, CAPE significantly increased GSH and GSH-Px levels in the serum and heart tissue $(p<0.05)$.

Conclusions. Caffeic acid phenethyl ester has beneficial effects on the tissues affected by periodontitis.

Keywords: free radicals, heart, caffeic acid phenethyl ester, inflammatory process, periodontal damage 


\section{Introduction}

Caffeic acid phenethyl ester (CAPE) is an active polyphenolic compound and a valuable element of propolis, which is a component of honey. It has numerous health benefits due to its antioxidative, antiproliferative, antitumoral, anti-inflammatory, immunomodulatory, and antineoplastic properties. An epidemiological study reported a reduction of blood pressure and the lessening of cardiovascular problems, mainly related to coronary heart disease, i.e., antithrombotic, anti-ischemic and vasorelaxant effects, following a regular intake of honey. ${ }^{1}$ The timely cardioprotective activity of CAPE, which decreased the diversion of xanthine oxidase (XO) and adenosine deaminase (ADA) as well as had a direct antioxidant effect, has been demonstrated in short-term myocardial ischemia in rats. ${ }^{2}$ Many studies have discussed the links between CAPE and mitogen-activated protein kinase (MAPK) pathways, which are an important part of treating cardiac disease. ${ }^{3,4}$ Caffeic acid phenethyl ester inhibits the stimulation of p38 MAPK, the activity of caspase- 3 , and the production of proinflammatory cytokines (interleukin (IL)- $1 \beta$ and tumor necrosis factor-alpha (TNF- $\alpha$ )). It also reduces cardiomyocyte apoptosis in cardiac tissues. ${ }^{5}$ The anti-inflammatory effect of CAPE is related to decreases in c-Jun N-terminal kinase, nuclear factor-kappa B (NF-kB) and cyclooxygenase (COX)-2 expression. ${ }^{6}$ Thus, the CAPE-based protection of cardiac myocytes is likely accomplished through inhibition - not only through the inhibition of inflammatory signaling, but also via the inhibition of cell death. ${ }^{6}$ Another useful effect of CAPE on cardiomyocyte cells is the control of accumulation of reactive oxygen species (ROS). Reactive oxygen species play a pivotal role in tissue harm and diseases. Several pathological conditions, such as cardiovascular diseases (CVD) (atherosclerosis, hypertension and congestive failure), can be stimulated when intracellular redox homeostasis is impaired. ${ }^{7,8}$ Cells always need oxygen for energy, which is obtained through oxidative phosphorylation. The production of adenosine triphosphate (ATP) begins with the reaction of 4 electrons and 4 protons joining $\mathrm{O}_{2}$ to form 2 water molecules $\left(\mathrm{H}_{2} \mathrm{O}\right)$. This process is sensitive, because, if a molecule of $\mathrm{O}_{2}$ gets only 1 electron, it is modified into a superoxide anion $\left(\mathrm{O}_{2}{ }^{--}\right)$. Hydrogen peroxide $\left(\mathrm{H}_{2} \mathrm{O}_{2}\right)$, hydroxyl radical $\left(\mathrm{OH}^{*}\right)$ and peroxynitrite $\left(\mathrm{ONOO}^{-}\right)$are examples of highly reactive ROS that can afford to keep more electrons as well as 4 protons to form $\mathrm{H}_{2} \mathrm{O}$. Antioxidant defense mechanisms act to prevent the pathophysiological damage caused by ROS. Nevertheless, oxidative stress can induce many different diseases, such as CVD (e.g., atherosclerosis or hypertension), diabetes mellitus, neurodegenerative disorders, rheumatoid arthritis, and periodontitis, as well as ageing., ${ }^{9,10}$

Periodontitis is a chronic inflammatory disease characterized by the destruction of periodontal tissues, such as connective tissue, bone, and teeth. ${ }^{11}$ Host and bacterial challenges are the key factors in the progression of peri- odontal disease and responses to systemic inflammation. ${ }^{12}$ In fact, physiological ROS, stimulated by immune cells, have antibacterial effects that support the immune regulation and host defense. Cytotoxic effects on cell growth and the cell cycle, the oxidative destruction of DNA and proteins, and the induction of gingival fibroblast apoptosis can all be stimulated by excessive ROS. When periodontal tissue destruction begins, the main role of ROS is as intracellular signaling molecules during osteoclastogenesis. As a result, bone destruction is indirectly induced. ${ }^{10,13}$

The triad of inflammation, oxidative stress and periodontitis has often been emphasized in previous studies. Inflammation and oxidative stress are the main elements of this pattern, and can also have pathological effects on other tissues. For example, periodontitis can have a negative effect on heart tissue because of increased pro-inflammatory cytokine levels and systemic oxidative stress. To some degree, oxidative stress can be blocked by autoimmune protective mechanisms, starting with the production of cytoprotective enzymes. ${ }^{10}$ One of these protective mechanisms may involve CAPE, as assessed in the present study. Specifically, we evaluated the antioxidant and anti-inflammatory effects of CAPE on cytokine levels and the oxidative status in the serum and heart tissue.

\section{Material and methods}

\section{Animals}

Twenty-eight male Wistar albino rats weighing approx. $200 \pm 20$ g were individually housed in plastic cages. The rats were kept in standard environmental conditions, fed with standard rat food and had tap water ad libitum. The room temperature was set at $24.0 \pm 0.6^{\circ} \mathrm{C}$ and the cages were kept in a $12 \mathrm{~h} / 12 \mathrm{~h}$ dark/light cycle (the lights were turned on at 07:30 a.m.). The animals were maintained and used in accordance with the Animal Welfare Act and the Guide for the Care and Use of Laboratory Animals prepared by Süleyman Demirel University, Isparta, Turkey (study approval No. 26-09/12).

\section{Induction of periodontitis}

The experimental animals were randomized into 3 groups: control group (C; $n=8$ ); periodontitis group (P; $n=10)$; and periodontitis + CAPE group (PC; $n=10)$. The ligature-induced periodontitis model is a consistent and safe method in which the accumulated plaque evokes periodontitis and stimulates the host response in the dentogingival region. ${ }^{14,15}$ Periodontitis is induced by placing ligatures on molar teeth. The waiting period for the periodontal reaction to begin should be less than 15 days. ${ }^{14}$ In this study, the histomorphometric analysis revealed that periodontal destruction successfully occurred in the experimental groups after 14 days (Fig. 1). 


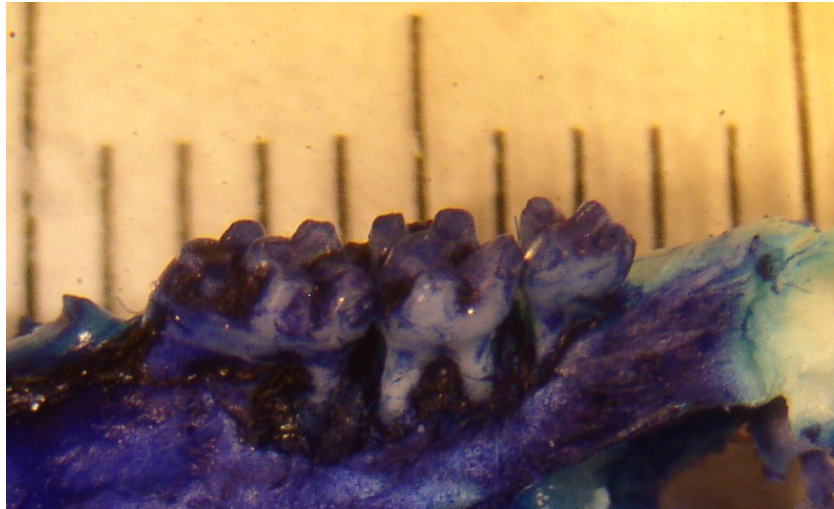

Fig. 1. Microscopic image of bone loss

magnification $\times 4$

Experimental periodontitis was induced under general anesthesia, using intramuscular ketamine $(90 \mathrm{mg} / \mathrm{kg})$ and xylazine $(10 \mathrm{mg} / \mathrm{kg})$ injection (Pfizer, Tadworth, UK). ${ }^{11}$ Sterile 3/0 silk ligatures (Doğsan, Istanbul, Turkey) were subgingivally wrapped around maxillary second molars in both groups for a duration of 14 days. ${ }^{14}$ Caffeic acid phenethyl ester (Sigma-Aldrich, St. Louis, USA) ${ }^{12}$ was administered at a dose of $10 \mu \mathrm{mol} / \mathrm{kg} /$ day via intraperitoneal injection for 14 days. $^{16}$ All chemicals were of analytical grade.

\section{Histomorphometric analysis}

After the rats were sacrificed under general anesthesia, the maxillae and hearts were resected and immediately fixed in $\mathrm{H}_{2} \mathrm{O}_{2}$ for $24 \mathrm{~h}$. The right maxillary halves were used for histomorphometric evaluation and stained with $1 \%$ methylene blue (Ceristain ${ }^{\circledR}$; Merck, Darmstadt, Germany) $(1 \mathrm{~g} / 100 \mathrm{~mL})$ diluted with water for $60 \mathrm{~s}$ to fix the cementoenamel junction (CEJ). The distance between $\mathrm{CEJ}$ and the alveolar bone crest $(\mathrm{ABC})$ was measured at 3 buccal points under a stereomicroscope (DP-Soft 3.2, Olympus Europa, Hamburg, Germany) at $\times 40$ magnification. Morphometric alveolar bone loss (ABL) was recorded using standardized digital photography (Leica MZ6; Leica, Wetzlar, Germany) and the images were analyzed using the ImageJ software, v. 1.46r (National Institutes of Health, Bethesda, USA).

\section{Heart tissue homogenization}

The hearts were cleaned with cold isotonic water, packaged in aluminum foil, and then stored at $-85^{\circ} \mathrm{C}$ in a deep freezer until analysis. Homogenization was performed at $16,000 \mathrm{rpm}$. The samples were placed in a refrigerated centrifuge (Kubota, Tokyo, Japan) and centrifuged at $3,220 \mathrm{rpm}$ for $30 \mathrm{~min}$ at $6^{\circ} \mathrm{C}$. The supernatant $1 / 1(\mathrm{v} / \mathrm{v})$ mixture of chloroform/ethanol $(3 / 5, \mathrm{v} / \mathrm{v})^{17}$ was transferred to glass tubes, vortexed, and then centrifuged at $3,220 \mathrm{rpm}$ for $40 \mathrm{~min}$ at $4{ }^{\circ} \mathrm{C}$.

\section{Determination of serum cytokine levels}

Centrifugation was used to separate the serum samples (at 1,500 rpm for $10 \mathrm{~min}$ at $4^{\circ} \mathrm{C}$ ). The samples were then poured into Eppendorf tubes and stored at $-20^{\circ} \mathrm{C}$ until testing began. Interleukin-1 $\beta$, IL-10 and TNF- $\alpha$ levels were assessed using enzyme-linked immunosorbent assay (ELISA) kits (eBioscience, Vienna, Austria) with a microplate reader (Infinite ${ }^{\circledR}$ M200; Tecan, Männedorf, Switzerland). The concentrations of IL- $1 \beta$, IL-10 and TNF- $\alpha$ were assayed from a standard curve and following the manufacturer's recommendations. The minimum assay detection limit was $4 \mathrm{pg} / \mathrm{mL}$ for IL- $1 \beta, 1.5 \mathrm{pg} / \mathrm{mL}$ for IL-10 and $11 \mathrm{pg} / \mathrm{mL}$ for TNF- $\alpha$.

\section{Determination of MDA, GSH and GSH-Px levels}

The method of Placer et al. was used for the analysis of lipid peroxidation (LPO) levels. ${ }^{18}$ Briefly, a pink color is a marker produced by mixing thiobarbituric acid (TBA) with MDA to design a colored MDA-TBA adduct. Lipid peroxidation levels, as presented by MDA, were observed using a spectrophotometric assay (Shimadzu UV-1800, Shimadzu Corp., Kyoto, Japan) at a wavelength of $532 \mathrm{~nm}$.

The samples were assessed for GSH at $412 \mathrm{~nm}$, using the method of Sedlak and Lindsay. ${ }^{19}$ Glutathione peroxidase spectrophotometric assessments were performed at $412 \mathrm{~nm}$ at $37^{\circ} \mathrm{C}$, based on the Lawrence and Burk technique. ${ }^{20}$ Malondialdehyde, GSH and GSH-Px levels were evaluated in the serum and heart tissue. The whole experimental protocol is presented in Fig. 2.

\section{Statistical analysis}

All statistical analyses were performed using the SPSS Statistics for Windows software, v. 17.0 (SPSS Inc., Chicago, USA). Group significance levels were assessed with the one-way analysis of variance (ANOVA). The results were reported as means $(M)$ and standard deviations $(S D)$. The Shapiro-Wilk test was used to assess the normal distribution of the variables. A $p$-value $<0.05$ indicated statistical significance. The independent $t$ test was used to determine differences between the groups.

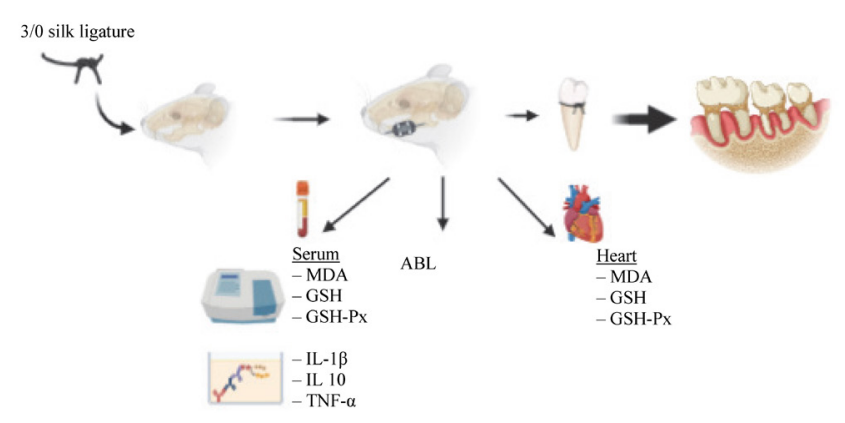

Fig. 2. Experimental protocol 


\section{Results}

Both experimental groups showed periodontitis symptoms. Alveolar bone loss occurred more commonly in the $\mathrm{P}$ group than in the $\mathrm{PC}$ group $(p<0.05)$. Inflammatory infiltration was observed in the $\mathrm{P}$ group as increased IL- $1 \beta$, IL-10 and TNF- $\alpha$ serum levels as compared to the control (all $p<0.05$ ). The 3 cytokines were downregulated due to the administration of CAPE. Hence, cytokine levels were downregulated in the $\mathrm{PC}$ group as compared to the $\mathrm{P}$ group $(p<0.05)$. Additionally, in the $\mathrm{PC}$ group, the antioxidative activity of CAPE was observed through the highest GSX and GSH-Px serum levels. Since periodontitis was induced without the administration of any agent, these 2 antioxidants were lower in the $\mathrm{P}$ group as compared to other groups $(p>0.05)$. The serum levels of the strongest oxidative marker - MDA - were significantly increased in the $\mathrm{P}$ group. For the other 2 groups, they were higher in the $\mathrm{PC}$ group than in the $\mathrm{C}$ group, although the difference was not statistically significant $(p>0.05)$.

Indeed, a significant relationship was observed between periodontitis, ROS and the affected heart in this study. The heart analysis almost repeated the pattern of the serum oxidant and antioxidant results. The highest MDA heart levels were observed in the P group and the lowest in the $\mathrm{C}$ group. However, the differences were not statistically significant $(p>0.05)$. These values returned to the original levels after the administration of CAPE. Additionally, GSH and GSH-Px heart levels were lower in the P group than in the $\mathrm{C}$ and PC groups $(p<0.05)$. Of course, the PC group had the highest levels due to oxidative stress. After the administration of CAPE, both antioxidant parameters were improved in the PC group $(p<0.05)$. All group comparisons are shown in detail in Table 1.

\section{Discussion}

The objective of this study was to reveal the effect of CAPE on cytokine levels and the oxidative status in the serum and heart tissue, using a rat periodontitis model. Our results demonstrated that CAPE is a good antioxidant and anti-inflammatory agent for decreasing the progression of periodontitis and its related effects on the heart in rats.

Caffeic acid phenethyl ester produces the most significant anti-inflammatory and antioxidant effects of all extracts of propolis. ${ }^{21}$ In recent studies using CAPE, it has been reported that CAPE has a protective effect with regard to cellular mechanisms in which oxidative stress is increased due to inflammation, and thus CAPE can protect many cell groups, including nerve cells, against oxidative damage. ${ }^{22,23}$ Caffeic acid phenethyl ester inhibits the lipoxygenase pathway of arachidonic acid metabolism and ROS production during inflammation. ${ }^{24}$ It is a potent inhibitor of NF-kB, which plays an important role in bone destruction. It has been found that these properties are helpful in healing bone defects and preventing alveolar bone loss. ${ }^{25,26}$

Hence, CAPE may be a beneficial additive agent in treating many diseases. Various studies have shown that CAPE and propolis reduce pro-inflammatory cytokine levels. ${ }^{27,28}$ Caffeic acid phenethyl ester was shown to relieve inflammatory pressure by decreasing the expression of NF-kB and COX-2 in an obese mouse model. ${ }^{29}$ The cardioprotective effects of CAPE following cardiac injury have been found to consist in decreasing apoptosis, oxidative stress and cardiomyocyte damage after suppressing pro-inflammatory cytokines, especially TNF- $\alpha$ expression. ${ }^{30}$ In addition, the oxidative stress induced by inflammation can provoke various pathological processes in the heart. The administration of CAPE was found to decrease MDA levels in aged rat heart. ${ }^{31}$ Increases in oxidative stress and the inflammatory response can result in CVD or negatively affect their course. Different studies have reported a possible crossconnection between MDA and heart disease via effects on genetics and cellular membranes in heart tissue. ${ }^{32}$ Tomofuji et al. reported that increased LPO products in periodontal inflammation contributed to oxidative DNA damage in the heart. ${ }^{33}$

Several studies have indicated that CAPE might be a regeneration alternative for bone resorption, as it improves the bone healing process and prevents receptor activator for NF- $\mathrm{kB}$ ligand (RANKL)-induced osteoclastogenesis. Previous studies have reported stimulating effects of antioxidants on bone healing in periodontitis. ${ }^{28}$ The formation of $\mathrm{OH} \cdot \mathrm{H}_{2} \mathrm{O}_{2}$ and $\mathrm{O}_{2}{ }^{-\cdot}$ radicals in periodontal tissue is mainly caused by neutrophils and macrophages. The $\mathrm{O}_{2}{ }^{--}$radical is thought to be associated with osteoclastic activity and bone resorption. It starts a dangerous attack against the host response and causes DNA damage due to enzymatic oxidation, vasodilation, the release of proinflammatory cytokines, such as IL-1, IL-6, IL-8, TNF- $\alpha$, TNF- $\beta$, and interferon, through NF- $\mathrm{B}$-based signal transduction pathways, and LPO activation related to bone resorption. Uncontrolled LPO can result in oxidative stress that severely damages cell integrity. ${ }^{17}$

Many studies have highlighted how an increased amount of pro-inflammatory cytokines can cause periodontal destruction. ${ }^{11,25}$ The administration of CAPE has been shown to slow down alveolar bone resorption and to decrease pro- and anti-inflammatory cytokine serum levels in periodontitis. ${ }^{28}$ Caffeic acid phenethyl ester was also shown to increase the filling rates of calvaria bone defects in rats. ${ }^{25}$ Our findings are similar to those of previous research. The highest amount of $\mathrm{ABL}$ occurred in the $P$ group and bone gain started after the administration of CAPE. Malondialdehyde levels increased and the activity of basic antioxidant enzymes, such as GSH and GSH$\mathrm{Px}$, decreased in experimental periodontitis. ${ }^{15}$ 
Table 1. Comparison of alveolar bone loss (ABL), and cytokine, oxidant and antioxidant levels in the 3 groups (ANOVA)

\begin{tabular}{|c|c|c|c|c|}
\hline Variable & Group C & Group P & Group PC & $p$-values \\
\hline $\begin{array}{l}\mathrm{ABL} \\
{[\mathrm{mm}]}\end{array}$ & $0.118 \pm 0.040$ & $0.718 \pm 0.242$ & $0.319 \pm 0.031$ & $\begin{array}{c}\text { C vs P (MD: }-0.600) \\
p<0.05^{*} \\
\text { C vs PC (MD: }-0.201) \\
p<0.05^{*} \\
\text { P vs PC (MD: } 0.399) \\
p<0.05^{*}\end{array}$ \\
\hline $\begin{array}{l}\| \mathrm{L}-1 \beta \\
{[\mathrm{pg} / \mathrm{mL}]} \\
\text { in the serum }\end{array}$ & $15.135 \pm 0.920$ & $92.231 \pm 1.730$ & $11.248 \pm 2.180$ & $\begin{array}{c}\text { C vs P (MD: }-77.096) \\
p<0.05^{*} \\
\text { C vs PC (MD: } 3.887) \\
p<0.05^{*} \\
\text { P vs PC (MD: } 80.983) \\
p>0.05\end{array}$ \\
\hline $\begin{array}{l}\text { IL-10 } \\
{[\mathrm{pg} / \mathrm{mL}]} \\
\text { in the serum }\end{array}$ & $1.245 \pm 0.840$ & $14.742 \pm 1.780$ & $2.578 \pm 0.630$ & $\begin{array}{c}\text { C vs P (MD: }-13.497) \\
p<0.05^{*} \\
\text { C vs PC (MD: }-1.333) \\
p<0.05^{*} \\
\text { P vs PC (MD: } 12.164) \\
p<0.05^{*}\end{array}$ \\
\hline $\begin{array}{l}\text { TNF-a } \\
{[\mathrm{pg} / \mathrm{mL}]} \\
\text { in the serum }\end{array}$ & $2.536 \pm 0.470$ & $16.574 \pm 0.730$ & $2.988 \pm 0.340$ & $\begin{array}{c}\text { C vs P (MD: }-14.038) \\
p<0.05^{*} \\
\text { C vs PC (MD: }-0.452) \\
p>0.05 \\
\text { P vs PC (MD: } 13.586) \\
p<0.05^{*}\end{array}$ \\
\hline $\begin{array}{l}\text { MDA } \\
\text { [ } \mu \mathrm{mol} / \mathrm{g} \text { of protein] } \\
\text { in the serum }\end{array}$ & $1.702 \pm 0.107$ & $2.462 \pm 0.270$ & $1.805 \pm 0.070$ & $\begin{array}{c}\text { Cvs P (MD: }-0.760) \\
p<0.05^{*} \\
\text { C vs PC (MD: }-0.103) \\
p>0.05 \\
\text { P vs PC (MD: } 0.657) \\
p<0.05^{*}\end{array}$ \\
\hline $\begin{array}{l}\text { GSH } \\
\text { [ } \mu \text { mol/g of protein] } \\
\text { in the serum }\end{array}$ & $2.562 \pm 0.080$ & $2.236 \pm 0.065$ & $2.851 \pm 0.219$ & $\begin{array}{c}\text { C vs } P(M D: 0.326) \\
p<0.05^{*} \\
\text { C vs PC (MD: }-0.289) \\
p>0.05 \\
\text { Pvs } P C(M D:-0.615) \\
p<0.05^{*}\end{array}$ \\
\hline $\begin{array}{l}\text { GSH-Px } \\
\text { [IU/g of protein] } \\
\text { in the serum }\end{array}$ & $60.361 \pm 8.962$ & $50.814 \pm 11.712$ & $80.136 \pm 5.777$ & $\begin{array}{c}\text { C vs P (MD: 9.547) } \\
p<0.05^{*} \\
\text { C vs PC (MD: }-19.775) \\
p>0.05 \\
\text { P vs PC (MD: }-29.322) \\
p<0.05^{*}\end{array}$ \\
\hline $\begin{array}{l}\text { MDA } \\
\text { [ } \mu \mathrm{mol} / \mathrm{g} \text { of protein] } \\
\text { in the heart }\end{array}$ & $20.341 \pm 3.014$ & $30.346 \pm 1.726$ & $20.634 \pm 2.493$ & $\begin{array}{c}\text { C vs P (MD: }-10.005) \\
p>0.05 \\
\text { C vs PC (MD: }-0.293) \\
p>0.05 \\
\text { P vs PC (MD: } 9.712) \\
p>0.05\end{array}$ \\
\hline $\begin{array}{l}\text { GSH } \\
\text { [ } \mu \text { mol/g of protein] } \\
\text { in the heart }\end{array}$ & $6.882 \pm 1.027$ & $4.205 \pm 0.647$ & $8.075 \pm 1.300$ & $\begin{array}{c}\text { Cvs } \mathrm{P}(\mathrm{MD}: 2.677) \\
p<0.05^{*} \\
\text { C vs } \mathrm{PC}(\mathrm{MD}:-1.193) \\
p<0.05^{*} \\
\text { Pvs PC (MD: }-3.870) \\
p<0.05^{*}\end{array}$ \\
\hline $\begin{array}{l}\text { GSH-Px } \\
\text { [IU/g of protein] } \\
\text { in the heart }\end{array}$ & $31.346 \pm 2.726$ & $29.856 \pm 2.269$ & $37.075 \pm 1.318$ & $\begin{array}{c}\text { Cvs P (MD: } 1.490) \\
p<0.05^{*} \\
\text { C vs PC (MD: }-5.729) \\
p<0.05^{*} \\
\text { P vs PC (MD: }-7.219) \\
p<0.05^{*}\end{array}$ \\
\hline
\end{tabular}

C - control group; P - periodontitis group; PC - periodontitis + caffeic acid phenethyl ester (CAPE) group; IL - interleukin; TNF-a - tumor necrosis factor-alpha; MDA - malondialdehyde; GSH - glutathione; GSH-Px - glutathione peroxidase; IU - international units; $M D$ - mean difference; * statistically significant ( $p<0.05$ ). Data presented as mean \pm standard deviation $(M \pm S D)$. 
Similar to previous studies, the present study found that IL-1 $\beta$, IL-10 and TNF- $\alpha$ serum levels were high in periodontitis. In the $\mathrm{P}$ group, increased MDA levels and decreased GSH and GSH-Px levels in the serum and heart tissue were found. The administration of CAPE to the PC group not only decreased the levels of MDA in heart tissue, it also increased GSH and GSH-Px levels in heart tissue.

A recent meta-analysis reported that an extra missing tooth due to periodontitis is associated with a $1.5 \%$ increment in the risk of heart disease and a $1.5 \%$ increment in the risk of stroke. ${ }^{34}$ Periodontal disease and CVD have nearly the same etiology, such as an increased risk with age, male sex, and history of smoking, diabetes, hypertension, and obesity. The relationship between periodontitis and CVD may be due to chronic inflammation and recurrent oral bacteremia, as inflammation plays a pivotal role in the pathogenesis of atherosclerosis.

\section{Conclusions}

To the best of our knowledge, this is the first experimental study to assess the effects of CAPE on ABL, cytokine levels and the oxidative status in the serum and heart tissue in an experimental periodontitis model. Our results suggest that periodontal infection may affect the heart due to increased inflammatory and oxidative reactions. We predicted that CAPE would protect periodontal tissues in periodontitis model rats via anti-inflammatory and antioxidant pathways. Caffeic acid phenethyl ester may induce a good host modulatory response to periodontitis. Given that the administration of CAPE reduced the inflammatory burden and systemic oxidative stress affecting heart tissue in our periodontitis model, these findings suggest that CAPE can protect against the adverse effects of excessive ROS in periodontitis, such as oxidative damage to heart tissue in CVD pathogenesis, etc. Clinical studies further evaluating the relationship between periodontal disease and CVD are needed to confirm these findings.

\section{ORCID iDs}

Umut Yiğit (1) https://orcid.org/0000-0001-8080-2932

Fatma Yeşim Kırzıoğlu (i) https://orcid.org/0000-0002-5240-4504

Özlem Özmen (1) https://orcid.org/0000-0002-1835-1082

Abdülhadi Cihangir Uğuz (1) https://orcid.org/0000-0002-5778-581X

\section{References}

1. Khalil MI, Sulaiman SA. The potential role of honey and its polyphenols in preventing heart diseases: A review. Afr J Tradit Complement Altern Med. 2010;7(4):315-321. doi:10.4314/ajtcam.v7i4.56693

2. Ince H, Kandemir E, Bagci C, Gulec M, Akyol O. The effect of caffeic acid phenethyl ester on short-term acute myocardial ischemia. Med Sci Monit. 2006;12(5):BR187-BR193.

3. Borrelli F, Maffia P, Pinto L, et al. Phytochemical compounds involved in the anti-inflammatory effect of propolis extract. Fitoterapia. 2002;73(Suppl 1):S53-S63. doi:10.1016/s0367-326x(02)00191-0
4. Mapesa JO, Waldschmitt N, Schmoeller I, et al. Catechols in caffeic acid phenethyl ester are essential for inhibition of TNF-mediated IP-10 expression through NF-KB-dependent but $\mathrm{HO}-1-$ and p38-independent mechanisms in mouse intestinal epithelial cells. $\mathrm{Mol}$ Nutr Food Res. 2011;55(12):1850-1861. doi: 10.1002/mnfr.201100105

5. Tan J, Ma Z, Han L, et al. Caffeic acid phenethyl ester possesses potent cardioprotective effects in a rabbit model of acute myocardial ischemia-reperfusion injury. Am J Physiol Hear Circ Physiol. 2005;289(5):H2265-H2271. doi:10.1152/ajpheart.01106.2004

6. Ren J, Zhang N, Liao H, et al. Caffeic acid phenethyl ester attenuates pathological cardiac hypertrophy by regulation of MEK/ERK signaling pathway in vivo and vitro. Life Sci. 2017;181:53-61. doi:10.1016/j. Ifs.2017.04.016

7. Chen CC, Kuo CY, Chen RF. Role of CAPE on cardiomyocyte protection via connexin 43 regulation under hypoxia. Int J Med Sci. 2016;13(10):754-758. doi:10.7150/ijms.15847

8. Craige SM, Kant S, Reif M, et al. Endothelial NADPH oxidase 4 protects ApoE-/- mice from atherosclerotic lesions. Free Radic Biol Med. 2015;89:1-7. doi:10.1016/j.freeradbiomed.2015.07.004

9. Reuter S, Gupta SC, Chaturvedi MM, Aggarwal BB. Oxidative stress, inflammation, and cancer: How are they linked? Free Radic Biol Med. 2010;49(11):1603-1616. doi:10.1016/j.freeradbiomed.2010.09.006

10. Kanzaki H, Wada S, Narimiya T, et al. Pathways that regulate ROS scavenging enzymes, and their role in defense against tissue destruction in periodontitis. Front Physiol. 2017;8:351. doi:10.3389/fphys.2017.00351

11. Loesche WJ, Grossman NS. Periodontal disease as a specific, albeit chronic, infection: Diagnosis and treatment. Clin Microbiol Rev. 2001;14(4):727-752. doi:10.1128/CMR.14.4.727-752.2001

12. Silva N, Dutzan N, Hernandez $M$, et al. Characterization of progressive periodontal lesions in chronic periodontitis patients: Levels of chemokines, cytokines, matrix metalloproteinase-13, periodontal pathogens and inflammatory cells. J Clin Periodontol. 2008;35(3):206-214. doi:10.1111/j.1600-051X.2007.01190.x

13. Shabbir A, Rashid M, Tipu HN. Propolis, a hope for the future in treating resistant periodontal pathogens. Cureus. 2016;8(7):e682. doi:10.7759/cureus.682

14. Kuhr A, Popa-Wagner A, Schmoll H, Schwahn C, Kocher T. Observations on experimental marginal periodontitis in rats. $J$ Periodontal Res. 2004;39(2):101-106. doi:10.1111/j.1600-0765.2004.00710.x

15. Yağan A, Kesim S, Liman N. Effect of low-dose doxycycline on serum oxidative status, gingival antioxidant levels, and alveolar bone loss in experimental periodontitis in rats. J Periodontol. 2014;85(3):478-489. doi:10.1902/jop.2013.130138

16. Sud'ina GF, Mirzoeva OK, Pushkareva MA, Korshunova GA, Sumbatyan NV, Varfolomeev SD. Caffeic acid phenethyl ester as a lipoxygenase inhibitor with antioxidant properties. FEBS Lett. 1993;329(1-2):21-24. doi:10.1016/0014-5793(93)80184-v

17. Chapple ILC. Oxidative stress, nutrition and neutrogenomics in periodontal health and disease. Int J Dent Hyg. 2006;4(Suppl 1):15-21; discussion 50-52. doi:10.1111/j.1601-5037.2006.00197.x

18. Placer ZA, Cushman LL, Johnson BC. Estimation of product of lipid peroxidation (malonyl dialdehyde) in biochemical systems. Anal Biochem. 1966;16(2):359-364. doi:10.1016/0003-2697(66)90167-9

19. Sedlak J, Lindsay RH. Estimation of total, protein-bound, and nonprotein sulfhydryl groups in tissue with Ellman's reagent. Anal Biochem. 1968;25(1):192-205. doi:10.1016/0003-2697(68)90092-4

20. Lawrence RA, Burk RF. Glutathione peroxidase activity in seleniumdeficient rat liver. Biochem Biophys Res Commun. 1976;71(4):952-958. doi:10.1016/0006-291x(76)90747-6

21. Ozturk G, Ginis Z, Akyol S, Erden G, Gurel A, Akyol O. The anticancer mechanism of caffeic acid phenethyl ester (CAPE): Review of melanomas, lung and prostate cancers. Eur Rev Med Pharmacol Sci. 2012;16(15):2064-2068.

22. Ho HC, Chang HC, Ting CT, Kuo CY, Yang VC. Caffeic acid phenethyl ester inhibits proliferation and migration, and induces apoptosis in platelet-derived growth factor-BB-stimulated human coronary smooth muscle cells. J Vasc Res. 2012;49(1):24-32. doi:10.1159/000329819

23. Fontanilla CV, Ma Z, Wei $X$, et al. Caffeic acid phenethyl ester prevents 1-methyl-4-phenyl-1,2,3,6-tetrahydropyridine-induced neurodegeneration. Neuroscience. 2011;188:135-141. doi:10.1016/j.neuroscience.2011.04.009 
24. Celli N, Dragani LK, Murzilli S, Pagliani T, Poggi A. In vitro and in vivo stability of caffeic acid phenethyl ester, a bioactive compound of propolis. J Agric Food Chem. 2007;55(9):3398-3407. doi:10.1021/jf063477o

25. Uçan MC, Koparal M, Ağaçayak S, et al. Influence of caffeic acid phenethyl ester on bone healing in a rat model. $J$ Int Med Res. 2013;41(5):1648-1654. doi:10.1177/0300060513490613

26. Toker H, Ozan F, Ozer H, Ozdemir H, Eren K, Yeler H. A morphometric and histopathologic evaluation of the effects of propolis on alveolar bone loss in experimental periodontitis in rats. $J$ Periodontol. 2008;79(6):1089-1094. doi:10.1902/jop.2008.070462

27. Orban Z, Mitsiades N, Burke TR Jr., Tsokos M, Chrousos GP. Caffeic acid phenethyl ester induces leukocyte apoptosis, modulates nuclear factor-kappa B and suppresses acute inflammation. Neuroimmunomodulation. 2000;7(2):99-105. doi:10.1159/000026427

28. Aral CA, Kesim S, Greenwell H, Kara M, Çetin A, Yakan B. Alveolar bone protective and hypoglycemic effects of systemic propolis treatment in experimental periodontitis and diabetes mellitus. J Med Food. 2015;18(2):195-201. doi:10.1089/jmf.2013.3137

29. Bezerra RMN, Veiga LF, Caetano AC, et al. Caffeic acid phenethyl ester reduces the activation of the nuclear factor $\mathrm{KB}$ pathway by high-fat diet-induced obesity in mice. Metabolism. 2012;61(11):1606-1614. doi:10.1016/j.metabol.2012.04.006

30. Bıçakçı N, Karaboğa I, Dökmeci AH, Güzel S, Fidanol Erboğa Z. Cardioprotective effect of caffeic acid phenethyl ester on cardiac contusion following blunt chest trauma in rats. Biotech Histochem. 2019;94(6):442-448. doi:10.1080/10520295.2019.1586999

31. Eşrefoğlu M, Gül $M$, Ateş B, Erdoğan A. The effects of caffeic acid phenethyl ester and melatonin on age-related vascular remodeling and cardiac damage. Fundam Clin Pharmacol. 2011;25(5):580-590. doi:10.1111/j.1472-8206.2010.00876.x

32. Köse $O$, Arabacı T, Yemenoglu $H$, et al. Influence of experimental periodontitis on cardiac oxidative stress in rats: A biochemical and histomorphometric study. J Periodontal Res. 2017;52(3):603-608. doi:10.1111/jre.12428

33. Tomofuji T, Ekuni D, Irie K, et al. Relationships between periodontal inflammation, lipid peroxide and oxidative damage of multiple organs in rats. Biomed Res. 2011;32(5):343-349. doi:10.2220/biomedres.32.343

34. Lee HJ, Choi EK, Park JB, Han KD, Oh S. Tooth loss predicts myocardial infarction, heart failure, stroke, and death. J Dent Res. 2019;98(2):164-170. doi:10.1177/0022034518814829 